\title{
FATORES QUE INFLUENCIAM A ADOÇÃO DE ARTEFATOS DE CONTROLE GERENCIAL NAS EMPRESAS BRASILEIRAS. UM ESTUDO EXPLORATÓRIO SOB A ÓTICA DA TEORIA INSTITUCIONAL
}

\section{FACTS THAT INFLUENCE THE ADOPTION OF MANAGERIAL CONTROL ARTIFACTS IN BRAZILIAN COMPANIES. AN EXPLORATORY STUDY FROM THE PERSPECTIVE OF THE INSTITUTIONAL THEORY}

\author{
JOSÉ CARLOS OYADOMARI \\ Doutorando em Ciências Contábeis pela \\ Universidade de São Paulo \\ Professor Assistente Associado do Centro de Ciências Sociais e \\ Aplicadas da Universidade Presbiteriana Mackenzie \\ E-mail: oyadomari@mackenzie.br \\ OCTÁVIO RIBEIRO DE MENDONÇA NETO \\ Doutor em Contabilidade e Atuária pela \\ Universidade de São Paulo \\ Professor Assistente Associado do Centro de Ciências Sociais e \\ Aplicadas da Universidade Presbiteriana Mackenzie \\ E-mail: mendonça@mackenzie.com.br
}

\author{
RICARDO LOPES CARDOSO \\ Doutor em Contabilidade e Controladoria pela \\ Universidade de São Paulo \\ Professor Titular do Departamento de Contabilidade \\ da Universidade Presbiteriana Mackenzie \\ E-mail: ricardo.cardoso@mackenzie.com.br
}

MARIANA PONCIANO DE LIMA

Graduada em Ciências Contábeis pela

Universidade Presbiteriana Mackenzie

E-mail: mariana@mackenzista.com.br

\section{Resumo}

O presente estudo tem um caráter exploratório e seu objetivo é entender, à luz da Teoria NeoInstitucional, a adoção de artefatos de contabilidade gerencial no ambiente empresarial brasileiro. Para tanto, foi utilizada uma amostra não probabilística de 27 empresas de médio e grande porte, para as quais se enviou um questionário estruturado com questões fechadas, construído a partir da Teoria Neo-Institucional e de pesquisas anteriores em Contabilidade Gerencial. Os dados obtidos foram analisados com base em técnicas de estatística descritiva e os resultados obtidos permitem concluir que: (1) há uma adoção do tipo cerimonial na implementação dos artefatos; (2) o mecanismo mimético é o mais importante na adoção desses artefatos; (3) a obtenção do conhecimento sobre novos artefatos ocorre, preponderantemente, pela forma de socialização do conhecimento; (4) as consultorias têm um papel importante na adoção dos artefatos; (5) a imposição dos acionistas é pequena, sendo, portanto, minimizado o mecanismo coercitivo; (6) a decisão da escolha dos artefatos é prerrogativa do corpo diretivo e gerencial da empresa. Deve-se considerar a limitação deste estudo em relação ao tamanho da amostra e às técnicas de análise dos dados. Para pesquisas futuras, sugere-se a ampliação da amostra, viabilizando o uso de técnicas multi-variadas.

Palavras-chave: Teoria Institucional; contabilidade gerencial; isomorfismo.

\begin{abstract}
The present study has an exploratory characteristic and seeks to understand, based on neoinstitutional theory, the adoption of managerial accounting artifacts in Brazilian business environment. To do so, a non-probability sample of 27 medium and large companies was used, which received a questionnaire with closed-ended questions, grounded on Neo-Institutional theory and on previous researches on managerial accounting. The data obtained were analyzed through descriptive statistics and the achieved results allow the following conclusions: (1) there is a usage of the ceremonial type when it comes to the artifact implementation; (2) the mimetic mechanism is the most important when these artifacts are adopted; (3) the knowledge obtained from new artifacts happens mainly through knowledge sharing; (4) the consultant plays a very important role on the artifacts adoption; (5) because shareholders imposing is low, the coercive mechanism is also lowered; (6) artifacts choice decision is a prerogative of the board of directors and of the companies manager. The limitation of this study should be taken into consideration when it comes to the sample size and the techniques used to analyze the data. The usage of a larger sample and multivariate techniques is recommended for future researching.
\end{abstract}

Key words: Institutional Theory, managerial accounting, isomorphism. 


\section{INTRODUÇÃO}

Diferentes técnicas têm surgido com o intuito de melhorar a gestão das organizações, mas a despeito da oferta e dos fatores que influenciam a demanda por essas novas técnicas gerenciais (GRANDLUND \& LUKKA, 1998), constatou-se que há uma baixa aderência da implementação dessas técnicas e de conceitos de contabilidade gerencial nas empresas (GUERREIRO et al. 2004; SOUZA et al. 2003; GRANDLUND, 2001; HANSEN et al. 2003; FREZATTI, 2005 , DIETSHCI e NASCIMENTO, 2006). Para Scapens (1994), a ordem é que se esqueça o gap e que se pesquise a prática de contabilidade gerencial. No Brasil destacam-se os trabalhos de Frezatti (2005), que identificou clusters com perfis de uso de práticas de contabilidade gerencial e Soutes (2006), que estudou as práticas de contabilidade gerencial e a sua relação com o desempenho empresarial, mas ainda são escassos os estudos empíricos que usam a abordagem da Teoria Institucional para explicar a adoção dos artefatos de contabilidade gerencial.

Cardoso et al. (2007, p. 416), discutindo sobre vertentes alternativas para estudos em Contabilidade Gerencial, afirmam que a vertente institucional abrange

[...] todo conjunto de métricas e instrumentos que compõem a contabilidade gerencial são convenções, partes de ambientes (legal, profissional, regulatório, social) institucionalizados, e que influenciam as escolhas na organização.

No tocante à Contabilidade, Pereira e Guerreiro (2005) explicam que a Teoria Institucional considera a contabilidade gerencial como uma instituição ou rotina dentro da empresa, sendo esta rotina amplamente aceita de forma inquestionável.

Burns e Scapens (2000) classificam a Teoria Institucional em três vertentes: New Institutional Economics (NIE), Old Institutional Economics (OIE), e New Institutional Sociology (NIS), sendo esta última a vertente adotada neste trabalho, com a terminologia Teoria Neo-Institucional, consoante com Vasconcellos (2007). Esta teoria (NIS) estabelece que as organizações não levem em conta somente aspectos econômicos nas decisões de estrutura e práticas gerenciais, mas que muitas dessas decisões decorram do processo de legitimação (DIMAGGIO \& POWELL, 1983).

Este trabalho vem se juntar a outros que buscam entender a adoção dos artefatos à luz da Teoria Neo-Institucional, como o de Zan (2006), que estudou dois artefatos da contabilidade gerencial sob a ótica institucional, e inspira-se nas sugestões para futuras pesquisas desenvolvidas por Oyadomari et al. (2007). O propósito é responder a seguinte questão: quais são os fatores que influenciam o processo decisório de adoção dos artefatos de controle gerencial nas empresas brasileiras, à luz da Teoria Neo-Institucional?

Para fins deste estudo, é necessário definir Teoria Neo-Institucional e Artefatos de Controle Gerencial conforme segue: (i) A Teoria Neo-Institucional é caracterizada como uma abordagem sociológica que explica que as organizações adotam determinadas práticas como formas de legitimação, e não prioritariamente por razões econômicas. 0 processo decorre da institucionalização das práticas, as quais passam a ser crenças inquestionáveis, aceitas e legitimadas pelo contexto social da organização; e (ii) Os Artefatos de Controle Gerencial podem ser caracterizados como técnicas de planejamento e controle de gestão, que envolvem processos de mensuração, acumulação e comunicação de informações monetárias e não-monetárias sobre aspectos das dimensões de desempenho da organização.

O objetivo geral deste trabalho, de natureza exploratória e caracterizado como um estudo empírico-téorico, é identificar os fatores que influenciam as empresas brasileiras no processo de adoção de práticas e instrumentos de contabilidade gerencial, sob a ótica da Teoria Neo-Institucional, agrupando-os de acordo com os tipos de isomorfismo. Como 
objetivo específico, coloca-se a identificação das práticas de contabilidade gerencial utilizadas pelas empresas.

\section{REFERENCIAL TEÓRICO}

\subsection{ISOMORFISMO COM BASE EM DIMAGGIO E POWELL E SCOTT}

DiMaggio e Powell, no artigo seminal de 1983, estudaram a homogeneidade em vez das diferenças entre as organizações. A idéia então predominante era a de que as organizações eram diferentes em termos de estrutura e comportamento, e essa diferenciação era deliberada, como forma de elas se ajustarem a fatores contingenciais, notadamente exógenos. A principal contribuição dos autores está na afirmação que a motivação para a burocratização e para mudanças organizacionais decorre menos de objetivos econômicos e mais em razão de outros processos que tornam as organizações mais semelhantes, sem necessariamente torná-las mais eficientes, mas com motivação de se obter legitimação.

Machado-da-Silva et al. (2005, p. 29) colocam que:

[...] legitimidade é a palavra-chave da teoria neo-institucional, pois é o elemento que permite a manutenção ou a mudança das instituições, questionamentos a respeito da adequação das práticas, normas e procedimentos em razões de pressões internas e externas podem impossibilitar a reprodução dos padrões institucionalizados, acarretando a perda da sua legitimidade [...].

Para Vasconcellos,

A teoria institucional difere ainda da teoria organizacional tradicional, no sentido em que afirma que a ação organizacional pode acontecer independentemente de condicionantes objetivos, racionais ou de eficiência, pois as organizações submetidas às forças de um setor institucional são levadas a adotar práticas socialmente legítimas e, pela adoção dessas práticas, aumenta a sua probabilidade de acesso a recursos escassos tais como capital, licenças, tecnologia, parcerias, etc. (VASCONCELLOS, 2007, p. 32)

A esse processo de homogeneização denominou-se Isomorfismo. Na definição de Hawley (1968 apud DIMAGGIO \& POWELL, 1983, p. 149), o isomorfismo é um processo restritivo que força um elemento de uma população a se parecer com os outros que enfrentam o mesmo conjunto de condições ambientais. Vasconcellos observa que o ponto central da teoria institucional é a "existência de mecanismos socioeconômicos que levam as organizações a adotarem formas e práticas organizacionais semelhantes.” (2007, p. 32). DiMaggio e Powell (1983) indicam que existem três mecanismos de mudança isomórfica institucional: o isomorfismo coercitivo, o isomorfismo mimético e o isomorfismo normativo, e se espera que cada um dos processos miméticos aconteça na ausência da evidência de que eles aumentariam a eficiência organizacional interna (DIMAGGIO \& POWELL, 2005).

Scott (1995) desenvolveu um enfoque analítico para o que chamou de pilares que sustentam as instituições. Posteriormente, esse enfoque foi ampliado em Scott (2001) que incorporou os mecanismos de isomorfismo de DiMaggio e Powell (1983), conforme pode ser visto no Quadro 1, a seguir. 


\begin{tabular}{|c|c|c|c|}
\hline & Pilar Regulatório & Pilar Normativo & Pilar Cognitivo-Cultural \\
\hline $\begin{array}{l}\text { Base da } \\
\text { submissão }\end{array}$ & Utilidade & Obrigação social & $\begin{array}{c}\text { Crença } \\
\text { Entendimento } \\
\text { Compartilhado }\end{array}$ \\
\hline Base da demanda & Regras regulatório & $\begin{array}{l}\text { Expectativas de } \\
\text { sustentação }\end{array}$ & Esquema constitutivo \\
\hline Mecanismo & Coercitivo & Normativo & Mimético \\
\hline Lógica & Instrumentalidade & Apropriação & Ortodoxia \\
\hline Indicadores & $\begin{array}{l}\text { Regras } \\
\text { Leis } \\
\text { Sanções }\end{array}$ & $\begin{array}{l}\text { Certificação } \\
\text { Acreditação }\end{array}$ & $\begin{array}{c}\text { Crenças comuns } \\
\text { Lógicas compartilhadas da } \\
\text { ação }\end{array}$ \\
\hline $\begin{array}{c}\text { Bases da } \\
\text { legitimidade }\end{array}$ & $\begin{array}{l}\text { Legalmente } \\
\text { sancionada }\end{array}$ & $\begin{array}{l}\text { Moralmente } \\
\text { governada }\end{array}$ & $\begin{array}{c}\text { Compreensível } \\
\text { Reconhecível } \\
\text { Culturalmente suportada }\end{array}$ \\
\hline
\end{tabular}

Quadro 1. Variações de ênfases: três pilares institucionais (SCOTT, 2001, p. 52, quadro adaptado)

0 isomorfismo coercitivo deriva de influências políticas e do problema de legitimação, e é resultado de pressões formais e informais, exercidas por outras organizações e pela sociedade em que as organizações atuam (DIMAGGIO \& POWELL, 1983). O Estado é um dos agentes que mais influenciam nesse tipo de isomorfismo quando, por exemplo, obriga determinadas organizações a adotarem normas de proteção ambiental por força de lei. Nas organizações, além do poder estatal, esse tipo de isomorfismo também decorre da estrutura de poder que a matriz exerce sobre uma subsidiária (por exemplo, empresas subsidiárias são obrigadas a adotar o mesmo plano de contas e práticas contábeis da matriz). Ainda no campo das organizações, é preciso atentar para outros grupos de stakeholders, os quais podem influenciar as empresas (por exemplo, ambientalistas, sem poder de lei, mas com forte poder coercitivo, podem pressionar pela adoção de ações ambientais). Em pesquisa sobre as práticas contábeis gerenciais efetivamente utilizadas pelas subsidiárias brasileiras de empresas multinacionais, Souza et al (2003) demonstraram ser prática normal seguir um padrão de procedimentos estabelecidos pela matriz no que se refere às práticas gerenciais.

Já o isomorfismo mimético resulta de respostas padrão para situações de incerteza, ou seja, quando a organização tem dúvidas sobre determinada decisão a ser tomada, ela recorre ao comportamento mimético, que se constitui em imitar as decisões de outras organizações tidas como referências no ambiente em que atuam. 0 mimetismo é também adotado como forma de legitimação, pois os administradores podem justificar suas posições frente às adversidades na base do "pelo menos estamos tentando" (DIMAGGIO \& POWELL, 2005), ou para se justificar perante os acionistas, investidores e credores, de que a organização está sob controle e utiliza as mais modernas técnicas gerenciais. Abernethy e Chua (1996) justificam que há uma motivação racional no comportamento mimético, alegando que esse tipo de comportamento minimiza os custos de pesquisa de soluções viáveis como, por exemplo, no caso da importação de práticas gerenciais japonesas pelas empresas ocidentais, bem como a implantação do Orçamento Base Zero na administração pública dos Estados Unidos, o qual foi trazido das experiências no setor privado. 0 mecanismo isomorfismo mimético se encontra no pilar cognitivocultural, tendo como base de legitimação a sustentação cultural e a noção de conceitualmente correto.

0 isomorfismo normativo é associado com a profissionalização e o seu fundamento é o de que as profissões, na busca de legitimação perante a sociedade, constroem uma base cognitiva comum de forma a possuírem uma identidade frente a outras profissões. Três fatores são importantes no processo de uniformização de conhecimentos e práticas: 
(i) a formação acadêmica; (ii) as associações de classe; e (iii) os processos de seleção/recrutamento de pessoal. Em todos eles ocorre um intenso processo de socialização. A formação do conhecimento é padronizada por meio da transmissão do conhecimento por professores que cobrem um conteúdo programático padrão; quando já atuantes, estes profissionais freqüentam associações profissionais ou órgãos técnicos os quais funcionam também como instrumentos de padronização; o último componente é a seleção destes profissionais para trabalharem nas organizações, onde também há um isomorfismo, pois a seleção é feita geralmente entre profissionais com características comuns, como formação escolar e experiência profissional (DIMAGGIO \& POWELL, 2005, p. 80).

$\mathrm{Na}$ ausência de uma regulamentação das práticas de contabilidade gerencial, há que se considerar o efeito dos livros texto na formação de um pensar comum dos profissionais de contabilidade gerencial. Scapens (1994) coloca que os livros-texto são parte da educação profissional dos contadores, contribuindo para a institucionalização das práticas.

\subsection{PROCESSO DE INSTITUCIONALIZAÇÃO COM BASE EM TOLBERT E ZUCKER}

Tolbert e Zucker (1999) desenvolvem o processo de institucionalização em quatro fases: inovação, habitualização, objetificação e sedimentação. A ocorrência de fatores exógenos provoca a necessidade de inovação. Na fase de habitualização, a adoção das práticas ocorre em organizações que estão vivenciando o mesmo tipo de problema, assim, é natural que elas levem em conta as soluções desenvolvidas por outras organizações (TOLBERT \& ZUCKER, 1999). Na fase de objetificação as organizações podem utilizar evidências de diversas fontes (noticiários, observação direta, cotação acionária etc.) para avaliar os riscos de adoção da nova estrutura, e também podem observar as atitudes dos competidores, visando manter sua competitividade relativa bem como mensurar a relação custo $x$ benefício da prática (TOLBERT \& ZUCKER, 1999). Nessa fase, destaca-se a importância dos champions, que são indivíduos com interesse material na definição das práticas. As autoras citam como exemplo os consultores de qualidade total que exerceram um movimento mundial pela implementação da Gestão da Qualidade Total, difundindo modelos, práticas e também usando procedimentos de certificação por meio das normas ISO 9000. A sedimentação ocorre quando a institucionalização sobrevive por várias gerações na organização, ou seja, ela passa a fazer parte da história da organização. Sobre os fatores que podem impedir a sedimentação, as autoras colocam que mesmo na ausência de grupos de oposição direta, o processo pode ser truncado pela falta de resultados palpáveis, mas observam que associar o uso de determinada estrutura à obtenção de resultados é muito difícil.

\subsection{PROCESSO CERIMONIAL COM BASE EM MEYER E ROWAN (1977)}

\subsubsection{ADOÇÃO DA LINGUAGEM ISOMÓRFICA}

É possível perceber como algumas expressões acabam sendo incorporadas pelas empresas e pelos acadêmicos e, embora no começo da divulgação possam ocorrer divergências de nomenclatura das técnicas ou estruturas, com o tempo uma única 
expressão prevalece sobre as demais. Esse fato é coerente com Meyer e Rowan (1977) para quem as organizações adotam uma mesma linguagem para nomear as estruturas organizacionais. Neste estudo trabalha-se com a hipótese de que as organizações adotam os nomes consagrados das técnicas.

\subsubsection{NECESSIDADE DE MOSTRAR RACIONALIDADE E USO DE RITUAIS}

Meyer e Rowan (1977) exemplificam como procedimentos técnicos de produção, técnicas contábeis, técnicas de seleção de pessoal ou de processamento de dados tornaram-se crenças inquestionáveis nas organizações. Um dos fatores facilitadores é que o uso de técnicas modernas possibilita aos administradores mostrar que há uma gestão responsável e, assim, evitar acusações futuras de negligência (MEYER \& ROWAN, 1977). Porém, a simples adoção não garante a legitimação, é necessário que a adoção seja percebida pelos stakeholders, de forma que, para atingir esse objetivo, é necessário cumprir um ritual de divulgação. Geralmente, a alta administração das empresas contrata empresas de consultoria para implementar determinado artefato, mesmo que a organização possua profissionais com competências para desenvolver tal atividade.

\section{METODOLOGIA}

Esta pesquisa possui natureza exploratória, pois busca ampliar os conhecimentos sobre o tema teoria neo-institucional e a adoção de artefatos de controle gerencial, tema pouco estudado no Brasil, com exceção dos trabalhos de Zan (2006), Abreu (2006), Frezatti et al (2007). Tal escolha se justifica, visto que o conhecimento sobre o problema abordado é bastante incipiente.

A amostra é não probabilística e foi extraída das revistas Valor 1.000 Maiores Empresas, edição de 2006, e Valor Grandes Grupos, edição 2007, nas quais estão listados os 200 maiores grupos do país, além de um cadastro próprio dos pesquisadores. Foram contatadas 214 empresas por correspondência eletrônica e, em seguida, foram realizados dois contatos telefônicos. Face ao pequeno número de respostas obtidas, optou-se por utilizar um cadastro de empresas usado em pesquisas anteriores, para a composição da amostra e obtenção dos contatos. Foi construído um questionário eletrônico a ser respondido por meio de uma página da Internet desenvolvida com esta finalidade. Das empresas contatadas, foram obtidas 27 respostas, das quais 10 empresas constam da relação Valor 1.000 Maiores Empresas, 6 constam da relação Valor Grandes Grupos, e 11 são empresas do cadastro próprio.

0 instrumento utilizado para a coleta dos dados foi aplicação de questionário. 0 questionário formulado contém 46 questões, sendo que 44 são fechadas, utilizando a escala Likert para identificar o grau de utilização das técnicas de Contabilidade Gerencial, as atitudes da empresa quanto à adoção das práticas de contabilidade gerencial e, finalmente, os fatores que influenciaram o conhecimento e a adoção das práticas utilizadas pelas empresas. 0 questionário contém ainda 2 questões, também fechadas, referente à contratação ou não de serviços de empresas de consultoria para implementar técnicas de Controle Gerencial e quanto ao retorno dos investimentos empregados em tais técnicas. Esse questionário foi pré-validado junto a dois pesquisadores de Contabilidade Gerencial. 


\section{ANÁLISE E DISCUSSÃO DOS RESULTADOS}

Em relação à qualificação dos respondentes, item fundamental para validar as respostas dos questionários, 23 respondentes ocupam cargo de diretor ou gerente; em relação à área de atuação, 24 respondentes ocupam posições nas áreas de finanças, relações com investidores, controladoria ou contabilidade; em relação à experiência na função, 23 respondentes possuem mais de 3 anos na função; em relação à formação acadêmica, 26 respondentes possuem titulação em cursos de pós-graduação.

Quanto às empresas, observa-se a predominância de empresas de capital aberto, totalizando 20 empresas; em relação ao ramo de atuação, há uma concentração em indústrias, com 16 respondentes. Quanto ao porte, identifica-se que a maior parte das empresas é de grande porte, pois 18 empresas possuem mais de 1.000 funcionários, sendo que dessas, 10 possuem mais de 5.000 empregados. Outro fator que identifica o tamanho das empresas é a Receita Líquida Anual: 16 empresas têm uma Receita superior a 500 milhões de reais, conforme se pode observar nas Tabelas 1 a 4 a seguir:

Tabela 1 - Estrutura Societária.

\begin{tabular}{|l|c|c|}
\hline Estrutura Societária & Frequiência & $\%$ \\
\hline S/A Fechada & 4 & $14,81 \%$ \\
\hline S/A Aberta & 20 & $74,07 \%$ \\
\hline Ltda & 3 & $11,11 \%$ \\
\hline Total geral & 27 & $100,00 \%$
\end{tabular}

Tabela 2 - Ramo de atividade.

\begin{tabular}{|l|c|c|}
\hline Ramo de atividade predominante & Frequiência & $\%$ \\
\hline Comércio & 1 & $3,70 \%$ \\
\hline Indústria & 16 & $59,26 \%$ \\
\hline instituições financeiras & 4 & $14,81 \%$ \\
\hline Serviços & 6 & $22,22 \%$ \\
\hline Total de empresas & $\mathbf{2 7}$ & $\mathbf{1 0 0 , 0 0 \%}$
\end{tabular}

Tabela 3 - Receita Líquida em 2006.

\begin{tabular}{|c|c|c|}
\hline Receita Líquida & Frequiência & $\%$ \\
\hline Não informado & 2 & $7,41 \%$ \\
\hline até 10 milhões & 3 & $11,11 \%$ \\
\hline até 50 milhões & 4 & $14,81 \%$ \\
\hline até 100 milhões & 2 & $7,41 \%$ \\
\hline até 500 milhões & 3 & $11,11 \%$ \\
\hline acima de 500 milhões & 13 & $48,15 \%$ \\
\hline Total geral & $\mathbf{2 7}$ & $\mathbf{1 0 0 , 0 0 \%}$ \\
\hline
\end{tabular}


Tabela 4 - Quantidade de Funcionários.

\begin{tabular}{|c|c|c|}
\hline Quantidade de Funcionários & Frequiência & $\%$ \\
\hline até 500 & 7 & $25,93 \%$ \\
\hline entre 500 e 1.000 & 2 & $7,41 \%$ \\
\hline entre 1.000 e 3.000 & 7 & $25,93 \%$ \\
\hline entre 3.000 e 5.000 & 1 & $3,70 \%$ \\
\hline acima de 5.000 & 10 & $37,04 \%$ \\
\hline Total geral & $\mathbf{2 7}$ & $\mathbf{1 0 0 , 0 0 \%}$ \\
\hline
\end{tabular}

No bloco de questões sobre as práticas contábeis gerenciais mais utilizadas, os respondentes deveriam escolher entre cinco opções fornecidas, as quais foram enumeradas de 0 a 4 - do índice mais baixo (Não Utilizo) ao mais alto (Utilizo sempre que necessário). A escolha desses artefatos considerou os estudos anteriores de Frezatti (2005) e de Braga e Frezatti (2007). Os resultados obtidos são apresentados na Tabela 5 a seguir.

Tabela 5 - Artefatos utilizados

\begin{tabular}{|l|c|c|}
\hline \multicolumn{1}{|c|}{ ARTEFATOS } & MÉDIA & DESVIO-PADRÃO \\
\hline EVA - Lucro Residual ou Econômico & 2,81 & 1,71 \\
\hline RSPL (retorno sobre patrimônio líquido) & 3,89 & 1,25 \\
\hline ROCE/ ROI (retorno capital investido) & 4,26 & 0,98 \\
\hline Market Value Added & 2,89 & 1,85 \\
\hline Outra métrica de Gestão Baseada em Valor & 2,81 & 1,71 \\
\hline EBITDA & 4,26 & 1,20 \\
\hline Orçamento Base Zero & 2,33 & 1,73 \\
\hline Planejamento Estratégico & 4,63 & 0,84 \\
\hline Balanced Scorecard & 3,00 & 1,88 \\
\hline ABC - Custo por Atividade & 2,48 & 1,58 \\
\hline Resultado por Unidade de Negócios & 4,22 & 1,25 \\
\hline Beyond Budgeting & 1,48 & 1,09 \\
\hline Custo Padrão & 3,37 & 1,88 \\
\hline Custo Variável & 3,85 & 1,49 \\
\hline Custo Meta & 2,89 & 1,74 \\
\hline Kaizen ou Six Sigma & 1,85 & 1,43 \\
\hline Orçamento Contínuo - Rolling Forecasting & 2,85 & 1,88 \\
\hline Orçamento Matricial & 2,26 & 1,53 \\
\hline
\end{tabular}

O Planejamento Estratégico destaca-se como artefato mais utilizado, o que pode ser justificado pelo fato dos respondentes pertencerem a empresas de grande porte, nas quais este mecanismo já está institucionalizado no ambiente empresarial brasileiro, consoante a pesquisa de Frezatti (2005). O EBITDA é bastante utilizado, apesar de ser um indicador muito criticado na literatura (FREZATTI \& AGUIAR, 2006), o que pode ser explicado pelo fato de 20 empresas serem de capital aberto, as quais divulgam EBITDA para os investidores. 0 mesmo acontece com o Resultado por Unidade de Negócio, que é 
uma exigência da CVM e, também, característico de grandes empresas operando em vários segmentos.

Já os artefatos mais contemporâneos da Gestão Baseada em Valor, como EVA e MVA, mostraram-se pouco utilizados, em contraposição aos artefatos mais tradicionais, como ROCE e ROI, que apresentaram uma utilização significativa. O Balanced Scorecard também se mostrou pouco utilizado pelos respondentes, o que contraria o argumento de Otley (1980), porém, dado que se trata de um artefato mais contemporâneo, pode-se entender que já está bastante institucionalizado. Esse resultado é coerente com pesquisas de Dietschi e Nascimento (2006).

Com relação às técnicas ligadas a Contabilidade de Custos, destacam-se o uso mais intenso do Custo Variável e o do Custo Padrão, que são ferramentas tradicionais, em contraposição ao menor uso do Custo $A B C$ e do Custo Meta, que são técnicas mais contemporâneas, confirmando os estudos de Souza et al. (2003). Quanto aos artefatos ligados às técnicas orçamentárias os mais contemporâneos têm menor uso, e o Beyond Budgeting, preconizado por Hope e Fraser (2003), mostrou-se o menos utilizado, o que confirma a utilização prioritária do orçamento nas empresas brasileiras.

O segundo bloco do questionário, continha questões que buscavam medir as práticas e atitudes presentes na organização e as opções versavam sobre o grau de concordância em relação às assertivas. As respostas foram mensuradas usando uma escala Likert, enumeradas de 1 (Discordo Totalmente) a 5 (Concordo Totalmente). Os resultados obtidos são apresentados na Tabela 6 a seguir.

Tabela 6 - Atitudes e Valores Organizacionais

\begin{tabular}{|c|c|c|}
\hline ATITUDES E VALORES & MÉDIA & $\begin{array}{l}\text { DESVIO- } \\
\text { PADRÃO }\end{array}$ \\
\hline 1. Valoriza a introdução de novas técnicas de Controle Gerencial. & 4,59 & 0,64 \\
\hline $\begin{array}{l}\text { 2. Tem como estratégia ser pioneira na adoção de técnicas de controle } \\
\text { gerencial. }\end{array}$ & 3,48 & 1,16 \\
\hline $\begin{array}{l}\text { 3. Considera que o ambiente organizacional deva sempre refletir as } \\
\text { melhores técnicas de Controle Gerencial adotadas no mercado. }\end{array}$ & 4,15 & 1,17 \\
\hline $\begin{array}{l}\text { 4. O não uso de determinada técnica é fator importante para o abandono } \\
\text { da mesma. }\end{array}$ & 3,44 & 1,40 \\
\hline $\begin{array}{l}\text { 5. O apoio dos gerentes é importante para o processo de implementação } \\
\text { da técnica. }\end{array}$ & 4,81 & 0,48 \\
\hline $\begin{array}{l}\text { 6. A empresa ao implementar uma nova técnica adota o nome consagrado } \\
\text { da mesma }\end{array}$ & 4,11 & 0,93 \\
\hline 7. A implementação de nova técnica é cuidadosamente planejada. & 4,22 & 1,05 \\
\hline $\begin{array}{l}\text { 8. A comunicação da adoção da nova técnica é feita por meio de reuniões } \\
\text { formais. }\end{array}$ & 4,33 & 0,73 \\
\hline $\begin{array}{l}\text { 9. A introdução de nova técnica é comunicada aos acionistas e } \\
\text { investidores. }\end{array}$ & 3,78 & 1,28 \\
\hline $\begin{array}{l}\text { 10. A empresa acredita que os stakeholders valorizam a introdução de novas } \\
\text { técnicas gerenciais. }\end{array}$ & 4,22 & 1,05 \\
\hline
\end{tabular}

As duas primeiras questões mostram que as empresas valorizam as novas técnicas, mas preferem não serem necessariamente as pioneiras na sua introdução, o que pode ser justificado pela questão do risco (ABERNETHY \& CHUA,1996). Essas respostas estão em 
consonância com a teoria do isomorfismo mimético, o qual se justifica pela necessidade das organizações gerenciarem os riscos implícitos nas incertezas. Já a terceira questão confirma a primeira, com ênfase na questão do mercado como sendo um instrumento que referenda as técnicas. Alinhar-se às melhores práticas de mercado é uma forma de se obter legitimidade, ampliando o grau de mimetismo de um setor. Assim, muitas vezes, adotar as práticas mais utilizadas e aceitas como melhores, pode servir como suporte ou justificativa para algumas decisões tomadas em momentos de incerteza. As questões de 6 a 8 confirmam a adoção do cerimonial apresentado por Meyer e Rowan (1977), manifestado pelas reuniões formais e ênfase no planejamento da implementação o que implica em um alto grau de simbolismo. A adoção do nome consagrado também reflete o mimetismo e a busca de legitimação perante aos pares internos e externos à organização.

As respostas às questões 9 e 10, mostram que se leva em conta a percepção dos stakeholders, embora a comunicação das novas técnicas não seja direcionada aos acionistas e investidores. É, também, reconhecida a importância da adesão dos gerentes para facilitar a implementação do artefato consoante. Já na questão da desinstitucionalização, a menor concordância de que a não utilização implique no abando do artefato valida o aspecto da legitimação e confirma a visão de que adotar o artefato não significa necessariamente o seu uso.

O terceiro bloco do questionário buscou evidenciar os mecanismos indutores da adoção ou abandono dos artefatos. A escala utilizada foi de 1, para nenhuma importância, a 5, para muita importância. Os respondentes foram estimulados a responder a seguinte questão: Classifique sob a ótica de grau de importância os fatores que estimularam a adoção ou abandono de técnicas de controle gerencial em sua empresa. A Tabela 7, a seguir, foi construída com a classificação do mecanismo mimético.

Tabela 7 - Fatores que influenciam adoção e abandono dos artefatos

\begin{tabular}{|c|c|c|c|}
\hline FATORES & MÉDIA & $\begin{array}{l}\text { DESVIO- } \\
\text { PADRÃO }\end{array}$ & ISOMORFISMO \\
\hline 1. A imposição da matriz/ holding/ acionista & 3,59 & 1,47 & coercitivo \\
\hline 2. A imposição de clientes/ fornecedores. & 3,19 & 1,49 & coercitivo \\
\hline 3. A credibilidade das práticas. & 4,78 & 0,51 & mimético \\
\hline 4. A experiência de outras empresas. & 4,48 & 0,64 & mimético \\
\hline $\begin{array}{l}\text { 5. A opinião/ recomendação de empresas de } \\
\text { Consultoria. }\end{array}$ & 4,15 & 0,86 & mimético \\
\hline 6. O desempenho econômico-financeiro. & 4,59 & 0,75 & \\
\hline $\begin{array}{l}\text { 7. A decisão do corpo diretivo e gerencial da } \\
\text { empresa. }\end{array}$ & 4,96 & 0,19 & \\
\hline 8. A imposição de órgãos reguladores. & 4,19 & 1,24 & coercitivo \\
\hline 9. A leitura de livros sobre o assunto. & 3,89 & 1,25 & normativo \\
\hline
\end{tabular}

Os resultados obtidos indicam que o fator mais importante continua sendo a decisão do corpo diretivo e gerencial da empresa, mostrando que, de fato, há um processo de autonomia nessas organizações, uma vez que a imposição da matriz/acionistas se mostrou bem menor. Isso pode ser explicado pela crescente separação entre propriedade e administração nas empresas brasileiras de capital aberto. Por outro lado, nota-se como importante a imposição dos órgãos reguladores, uma vez que eles desempenham importante papel nas questões de contabilidade financeira e na sua divulgação ao 
mercado, o que pode gerar impactos nas práticas de contabilidade gerencial, já que a dissociação entre a contabilidade financeira e a gerencial é bastante tênue.

Um resultado que contraria, em parte, o pressuposto da Teoria Neo-Institucional é aquele que mostra que os executivos levam em conta a necessidade de melhorar o desempenho econômico-financeiro das empresas como um fator que influencia a adoção ou abandono de uma técnica de controle gerencial. Nesse ponto, talvez se devesse considerar que a obtenção de desempenho econômico-financeiro, em essência, também se trata de um processo de legitimação perante os acionistas e os stakeholders como um todo.

0 isomorfismo mimético pode ser percebido pelo fato de as empresas atribuírem um alto grau de importância à experiência de outras empresas, a credibilidade das práticas e a recomendação de empresas de consultoria, corroborando a teoria também no aspecto da legitimação. A questão sobre Consultoria ratifica o Isomorfismo Mimético e Normativo, já que essas empresas, muitas vezes, apresentarem soluções prontas, contribuindo para o grau de homogeneidade de um setor. Esse é um fator importante no processo decisório, na opinião dos respondentes.

Formulou-se ainda uma questão especifica sobre a utilização dos serviços de Consultoria, especialmente por ser essa uma etapa considerada comum no procedimento de legitimação. Essa questão apresentou os seguintes resultados, sintetizados na Tabela 8 a seguir:

Tabela 8 - Utilização de serviços de consultoria nos últimos 3 anos

\begin{tabular}{|l|c|c|}
\hline \multicolumn{1}{|c|}{ Uso de Consultorias nos últimos 3 anos } & Frequiência & $\%$ \\
\hline Sim & 11 & $40,74 \%$ \\
\hline Não & 16 & $59,26 \%$ \\
\hline Total geral & $\mathbf{2 7}$ & $\mathbf{1 0 0 \%}$ \\
\hline
\end{tabular}

Portanto, mesmo sendo considerado um fator importante no processo decisório, a maior parte dos respondentes não utilizou esse tipo de serviço nos últimos três anos, ainda que $40,74 \%$ não seja um índice desprezível. Embora as consultorias tenham um papel técnico, há que se considerar o aspecto de legitimação conferido por elas, uma vez que: 1) são um agente externo e têm sua legitimidade reconhecida por ter implementado tal artefato em outras empresas tidas como referência; 2) dado os altos custos com o projeto e o envolvimento das pessoas, sua utilização é uma forma de comunicar ao público interno que o projeto é importante; 3) as consultorias funcionam, também, como uma possível justificativa no caso da implantação não obter êxito, já que o gestor pode alegar que fez tudo certo, ou seja, contratou empresas de consultoria de renome e, portanto, a culpa não é unicamente dele como gestor.

O último bloco buscou identificar como a empresa toma conhecimento das novas técnicas de controle gerencial. As respostas foram mensuradas segundo uma Escala Likert com 1 para nenhuma importância e 5 para muita importância. Aos respondentes foi proposta a seguinte pergunta: Assinale a importância desses fatores para que a empresa tome conhecimento das novas técnicas de controle gerencial. Os resultados obtidos são apresentados na Tabela 9 a seguir: 
Tabela 9 - Formas como a empresa adquire informações sobre novas técnicas de controle gerencial

\begin{tabular}{|l|r|c|}
\hline Formas de obtenção de informações & MÉDIA & $\begin{array}{c}\text { DESVIO- } \\
\text { PADRÃO }\end{array}$ \\
\hline Seminários, Congressos e Palestras & 4,30 & 0,87 \\
\hline Revistas e Jornais de Negócios & 4,30 & 0,82 \\
\hline Consultorias & 4,22 & 0,89 \\
\hline Visitas a outras empresas do setor & 4,19 & 1,11 \\
\hline Reuniões em entidades profissionais ou patronais & 3,89 & 1,12 \\
\hline Conversas informais com outros colegas de profissão & 4,04 & 1,19 \\
\hline A leitura de livros sobre o assunto & 4,22 & 1,12 \\
\hline
\end{tabular}

Dos dados dessa tabela, depreende-se a importância dos mecanismos normativos, destacando-se os seminários e palestras, e os casos relatados nas revistas e jornais de negócios. Também os livros, as consultorias e as visitas a outras empresas do setor mostram sua importância na obtenção da informação sobre novas práticas, confirmando a hipótese de socialização do conhecimento. Os seminários contribuem para a construção da base comum do conhecimento profissional, pois, geralmente, são desenvolvidos de forma a relatar casos de sucesso em empresas, com a participação dos próprios profissionais envolvidos no caso e, também, por profissionais de consultoria. Assim, é provável que os profissionais participantes de seminários sintam-se motivados a adotar as mesmas práticas relatadas por colegas de profissão. A mídia especializada tem um papel importante para atingir os objetivos de institucionalização, propagando o uso dos artefatos gerenciais para o grande público. Pode-se também citar o caso de representantes da mídia escolhidos para fazer o curso de avaliação de financiamentos de projetos de produção limpa (BENNETT et al., 2004).

Quanto ao papel das empresas de consultoria, entende-se que essas são aliadas dos administradores na legitimação das decisões tomadas pela organização. As empresas buscam esses profissionais de forma a legitimar o processo de introdução de um novo artefato. Nesse caso, o que conta é a experiência dos consultores na realização de trabalhos similares em empresas que possam ser classificadas como referências. A importância dos livros confirma o argumento de Scapens (1994).

Por fim, foi formulada uma questão relacionada com o retorno sobre investimentos realizados para a implantação das novas práticas de controle gerencial e os resultados obtidos são apresentados na Tabela 10 a seguir.

Tabela 10 - Retorno dos investimentos em novas técnicas de controle gerencial

\begin{tabular}{|l|c|c|}
\hline $\begin{array}{l}\text { Em relação ao Retorno dos Investimentos nas técnicas de controle } \\
\text { gerencial }\end{array}$ & Frequiência & $\%$ \\
\hline Houve o retorno esperado. & 18 & $66,67 \%$ \\
\hline Houve retorno, mas menor que o esperado. & 3 & $11,11 \%$ \\
\hline Houve retorno, acima do esperado. & 1 & $3,70 \%$ \\
\hline Ainda não houve retorno dos investimentos empregados. & 1 & $3,70 \%$ \\
\hline Não medimos o retorno desses investimentos. & 4 & $14,81 \%$ \\
\hline Total geral & $\mathbf{2 7}$ & $\mathbf{1 0 0 \%}$ \\
\hline
\end{tabular}

Esses resultados mostram que $70 \%$ dos respondentes afirmaram que houve o retorno esperado ou mais que o esperado, apenas $10 \%$ salientaram que o retorno foi menor que o esperado e $14 \%$ observaram não avaliar o retorno desses investimentos, o que sugere que os fracassos nas tentativas de implementação de novas técnicas podem ter sido em 
pequena quantidade e, portanto, os profissionais não são mais tão refratários à implementação de processos de mudanças. Cabe ressaltar, contudo, que as respostas a essa questão podem também conter um viés, dado que os respondentes são da área de controle e finanças, e parece ser descabido que eles não façam medições de retorno. Porém, ela é coerente com a resposta da obtenção de desempenho econômico-financeiro como um dos principais motivos para adoção dos artefatos. O percentual não desprezível de respondentes que alegaram não medir o retorno dos investimentos ressalta a dificuldade dessa mensuração, o que é coerente com o Tolbert e Zucker (1999), para quem é muito difícil associar uso de técnicas com obtenção de resultados.

\section{CONSIDERAÇÕES FINAIS}

Este estudo de natureza exploratória buscou identificar os fatores que influenciam a adoção dos artefatos de controle gerencial, à luz da Teoria Neo-Institucional.

Os resultados obtidos permitem concluir que: (1) há uma adoção do tipo cerimonial na implementação dos artefatos; (2) o mecanismo mimético é o mais importante na adoção dos mesmos; (3) a obtenção do conhecimento sobre novos artefatos ocorre, preponderantemente, pela forma de socialização do conhecimento, por meio de seminários, visitas a outras empresas, consultorias e notícias de jornais e revistas de negócios (4) as consultorias têm um papel importante na adoção dos artefatos; (5) a imposição dos acionistas é pequena, sendo portanto minimizado o mecanismo coercitivo, (6) a decisão da escolha dos artefatos é prerrogativa do corpo diretivo e gerencial da empresa, (7) os artefatos utilizados com maior freqüência são os classificados como tradicionais.

A principal contribuição desse estudo foi a de validar os pressupostos da Teoria Neo-Institucional, mostrando que o pilar cognitivo-cultural, o qual envolve aspectos da socialização do conhecimento, operacionalizado pelo mecanismo isomórfico mimético, é o principal pilar para explicar a adoção dos artefatos de controle gerencial. Outra contribuição importante é a questão de considerar a obtenção de desempenho econômicofinanceiro como sendo, também, um processo de legitimação, já que a alta competitividade do ambiente atual leva as organizações a buscarem um desempenho superior ao de seus competidores. Outras contribuições deste estudo sugerem importantes insights para aqueles que desenvolvem artefatos de controle gerencial, os quais devem considerar a questão dos seminários, consultorias, livros e revistas de negócios no processo de institucionalização.

Este estudo tem algumas limitações e, portanto, seus resultados não podem ser generalizados. A primeira limitação se refere ao fato de se utilizar uma amostra nãoprobabilística e de apenas 28 respondentes; a segunda limitação se refere à possibilidade da ocorrência de viés nas respostas a algumas questões; a terceira limitação diz respeito a não utilização de técnicas estatísticas de análise multi-variada, limitadas pela quantidade de respondentes, e a última está relacionada com o questionário que pode não ter capturado corretamente os constructos da Teoria Neo-Institucional. Apesar dessas limitações, entende-se que este estudo é relevante para o entendimento das influências da Teoria Neo-Institucional na adoção de artefatos de controle gerencial.

Como recomendações para futuras pesquisas, sugere-se a ampliação da amostra, bem como a reformulação de algumas questões no tocante à mensuração do retorno dos investimentos em novos artefatos de controle gerencial. Outros recortes sugeridos são os estudos em empresas de culturas organizacionais diferentes, e a inclusão de aspectos contingenciais. 


\section{REFERÊNCIAS}

ABERNETHY, M. A.; CHUA, W. F. A Field Study of Control System "Redesign": The Impact of Institutional Processes on Strategic Choice. Contemporary Accounting Research, v. 13, fall, p. 569 - 606, 1996.

ABREU, L. R. B. C. Grau de institucionalização e a sua influência na percepção de desempenho no processo de planejamento: um estudo de caso sob a ótica da teoria institucional. São Paulo: 2006. Dissertação (Mestrado em Controladoria e Contabilidade). Universidade de São Paulo - Faculdade de Economia e Administração, São Paulo, 2006.

BENNETT, M.; BOUMA, J. J., CICCOZZI, E. An institutional perspective on the transfer of accounting knowledge: a case study. Accounting Education. 13, 3, p. 329 - 346, sep. 2004.

BRAGA, A. A.; FREZATTI, F. Sistema de Controle Gerencial e Contextos de Processo de Estratégia: Contribuições da Teoria da Contingência. Congresso USP de Controladoria e Contabilidade, 7, São Paulo - SP. Anais... São Paulo - SP, 2007.

BURNS, J.; SCAPENS, R. W. Conceptualizing management accounting change: an institutional framework. Management Accounting Research, v.11, p. 3 - 25, 2000.

CARDOSO, R. L.; MÁRIO, P. C.; AQUINO, A. C. B. Contabilidade Gerencial: mensuração, monitoramento e incentivos. São Paulo: Atlas, 2007.

DIETSCHI, D. A.; NASCIMENTO, A. M. Uma investigação do foco prioritário do Balanced Scorecard. In: Congresso USP de Controladoria e Contabilidade, 6, 2006, São Paulo - SP. Anais... São Paulo - SP, 2006.

DIMAGGIO, P. J; POWELL, W. W. The Iron Cage Revisited: Institutional Isomorphism And Collective Rationality In Organizational Fields. American Sociological Review, v. 48, 2, apr. p. 147 - 160, 1983.

. A Gaiola de Ferro Revisitada: Isomorfismo institucional e racionalidade coletiva nos campos organizacionais. Revista de Administração de Empresas, São Paulo, v. 45, 2, p. 23 - 33, abr/jun. 2005.

FREZATTI, F . Management Accounting Profile of Firms Located in Brazil: a Field Study. Revista de Administração Contemporânea, v. 9, 2 ed. especial, p.147-165, 2005.

.; AGUIAR, A. A. The Use of EBITDA for Management Control: Potential Distortions and Limitations. International Conference on Theory and Practice in Performance Measurement and Management, 5, 2006, Londres - UK. Proceedings Londres, 2006.

.; REZENDE, A. J. Strategic responses do institutional pressure and success in achieving budget targets: a survey at a multinational company. International Journal of Information Management. v. 15, 2, p. 50 - 66, 2007.

GRANDLUND, M.; LUKKA; K.. It's a Small World of Management Accounting Practices. Journal of Management Accounting Research, v. 10, p. 133 -153, 1998.

Towards explaining stability in and around management accounting systems. Management Accounting Research. v. 12, 2, p. 141 - 166, jun. 2001.

GUERREIRO, R.; FREZATTI, F.; CASADO, T. Em busca do entendimento da formação dos hábitos, rotinas e instituições da contabilidade gerencial. In: Congresso USP de Controladoria e Contabilidade, 4, 2004, São Paulo - SP. Anais... São Paulo- SP, 2004. 
HANSEN, S. C.; OTLEY, D. T.; STEDE, W. A. Van der. Practice Development in Budgeting: An Overview and Research Perspective. Journal of Management Accounting Research, v. 15, p. 96 - 116, 2003.

HOPE, J., FRASER, R. Beyond Budgeting: How Managers Can Break Free from the Annual Performance Trap. Boston: Harvard Business School, 2003.

MACHADO-DA-SILVA, C. L., FONSECA, V. S.; CRUBELLATE, J. M. Estrutura, Agência e Interpretação: Elementos para uma Abordagem Recursiva do Processo de Institucionalização. Revista de Administração Contemporânea, 1, p. 9 - 39, 2005.

MEYER, J. W.; ROWAN, B. Institutionalized Organizations: Formal Structure as Myth and Ceremony. The American Journal of Sociology, v. 83, 2, p. 340 - 363, 1977.

OTLEY, D.T. The contingency theory of management accounting: achievements and prognosis. Accounting, Organizations and Society, Oxford, v. 5, 4, p. 413 - 428, 1980.

OYADOMARI, J. C. T.et. al. A Institucionalização da VBM Value Based Management como prática de contabilidade gerencial: uma Análise à luz da NIS New Institutional Sociology. In: Congresso USP de Controladoria e Contabilidade, 7, 2007 São Paulo - SP. Anais... São Paulo - SP, 2007.

PEREIRA, C. A.; GUERREIRO, R. Avaliação do Processo de Mudança da Contabilidade Gerencial sob o Enfoque da Teoria Institucional: O Caso do Banco do Brasil. ENANPAD, 2005. Rio de Janeiro - RJ. Anais... Rio de Janeiro - RJ, 2005.

SCAPENS, R.W. Never mind the gap: towards an institutional perspective on management accounting practice. Management Accounting Research, v. 5, 3/4, p. $301-321$, sep/dec. 1994.

SCOTT, W. R. Institutions and Organizations. California: Sage, 2001.

Institutions and Organizations. California. Sage, 1995.

SOUTES, D. O. Uma investigação do uso de artefatos da contabilidade gerencial por empresas brasileiras. São Paulo: 2006. Dissertação (Mestrado em Controladoria e Contabilidade) - Universidade de São Paulo - Faculdade de Economia e Administração, São Paulo, 2006.

SOUZA, M. A.; LISBOA, L. P.; ROCHA, W. Práticas de Contabilidade Gerencial Adotadas por Subsidiárias Brasileiras de Empresas Multinacionais. Revista de Contabilidade e Finanças USP, , 32 p. 40 - 57, mai/ago. 2003.

TOLBERT, P. S.; ZUCKER, L. G. A Institucionalização da Teoria Institucional. In: CLEGG, S. R.et al (Orgs.). Handbook de Estudos Organizacionais. v. 1, São Paulo: Atlas, 1999.

VASCONCELLOS, F. Dinâmica Organizacional e Estratégia: imagens e conceitos. São Paulo: Atlas, 2007.

ZAN, A. Mudanças na contabilidade gerencial de uma organização: estudo de caso com diagnóstico institucional. São Paulo: 2006, Dissertação (Mestrado em Controladoria e Contabilidade) - Universidade de São Paulo - Faculdade de Economia e Administração, São Paulo, 2006. 


\section{ENDEREÇO DOS AUTORES}

Universidade Presbiteriana Mackenzie Centro de Ciências Sociais e Aplicadas R. da Consolação, 896 - Consolação Prédio Rev. Modesto Carvalhosa Sao Paulo, SP - Brasil 01302-907
Universidade Presbiteriana Mackenzie R. Major Sertório, 733 - Vila Buarque Sao Paulo, SP - Brasil 01222-001

Fundação Getúlio Vargas - RJ

Praia de Botafogo, 190, sala 501 - Botafogo

Rio de Janeiro, RJ - Brasil

22250-900 